\title{
Knowledge and Usage of Cervical Cancer Screening for Cancer Prevention by Reproductive Age Women
}

\author{
Justina I. Ofuebe ${ }^{1}$, Lois N. Omaka ${ }^{2}$, Blessing O. Asogwa ${ }^{1}$, Michael A. Agu ${ }^{1} \&$ Uchenna C. Ugwu ${ }^{1}$ \\ ${ }^{1}$ Department of Human Kinetics and Health Education, Faculty of Eduucation, University of Nigeria, Nsukka, \\ Enugu State, Nigeria \\ ${ }^{2}$ Department of Human Kinetics and Health Education, Faculty of Eduucation, Ebonyi State University, Abakaliki, \\ Ebonyi State, Nigeria \\ Correspondence: Blessing O. Asogwa, Department of Human Kinetics and Health Education, Faculty of \\ Eduucation, University of Nigeria, Nsukka, Enugu State, Nigeria. Tel: 234-803-894-3770. E-mail: \\ asogwablessing45@gmail.com
}

\author{
Received: April 21, 2019 Accepted: May 12, 2019 Online Published: June 4, 2019 \\ doi:10.5539/gjhs.v11n7p47 URL: https://doi.org/10.5539/gjhs.v11n7p47
}

\begin{abstract}
Cervical cancer-CCa screening is an effective measure mapped out for preventing cancer occurrences in women. This study determined the status of knowledge and usage of $\mathrm{CCa}$ screening for cancer prevention among reproductive age Nigerian women. The study was based on descriptive research design and was conducted in Nigeria, from October 2017 to April 2018 and comprised of reproductive age women. The participants, aged 15-49 years, were vulnerable to $\mathrm{CCa}$. The instrument used for data collection was structured questionnaire. Statistical Package for Social Science version 21 was used for data analysis. All the participants were Nigerians totalling 1300. Of all, 1249(96.1\%) completed the questionnaire correctly. Majority of the participants were: Christians 825(66.0\%), Single 695(55.6\%), aged 26-35 years 673(53.8\%), and had Secondary education 753(60.2\%). A greater proportion of the participants 1073(86.7\%) knew about CCa screening. Among them, only 513(41.7\%) were screened. The status of knowledge and usage of $\mathrm{CCa}$ screening varied within variables. A statistically significant difference was observed with regards to Age by birth (P-value $<0.05)$ while none existed on marital status, religion and educational level ( $\mathrm{P}$-value $>0.05$ ). There is obvious gap between what is known about CCa screening service for cancer prevention and the actual usage by the women. The majority of the women knew about the available services but only few of them had used it. This implies that there is obvious imbalance between the quality of knowledge of a given health service and the actual usage.
\end{abstract}

Keywords: cervical cancer, screening service, knowledge, usage, women

\section{Introduction}

The increasing cases of morbidity and mortality due to cervical cancer - CCa particularly in developing regions such as Nigeria have constituted a huge concern to public health sector and other healthcare professionals. Cervical cancer is preventable if appropriate screening exercise is routinely applied (Mahlck, Jonsson, \& Lenner, 1994; Elovainio, Nieminen, \& Miller, 1997; Mutyaba, Mmiro, \& Weiderpass, 2006). This screening service is one of the most effective strategies and reliable public health initiative mapped out to prevent the occurrences of CCa (Dusek et al., 2018). It is expected that the screening exercise would not only enhance early detection, but also aid in the prevention and subsequent treatment of the disease. Surprisingly, the alarming rates of CCa incidence and occurrences worldwide (Anantharaman, Sudharshini, \& Chitra, 2013; Ferlay et al., 2013) and the obvious consequences on womens' health particularly in developing countries (Adewole, Benedet \& Crain, 2005; Ferlay et al., 2013; Bray et al., 2013; Mutyaba, Mmiro, \& Weiderpass, 2006) has dwindled the expectations. Although, low awareness about the risk factors of cancer is already pronounced (Sa'aku, Omaka-Amari, Agu, Ugwu, \& Ugwu, 2019) yet, it is still quite worrisome and has placed a huge doubt on whether people equally know about the CCa screening services and the subsequent usage. The above situation motivated the researchers to conduct this study using the reproductive age women in developing country -Nigeria. The reproductive age women are the most vulnerable group to CCA disease and thus making the usage of the CCa screening indispensible for ensuring safety, prevention and quality of health. The study was set to determine the status of knowledge and usage of $\mathrm{CCa}$ screening for cancer prevention among reproductive age Nigerian women and also to verify the null hypotheses of no significant difference within variables. As one of the expectations of the researchers, the outcome of this 
research would serve as a veritable tool in designing programmes on cervical cancer for the women. Currently, this research is the first survey of this kind in Nigeria. Specifically, the study seeks to determine:

1) The status of knowledge of cervical cancer screening for cancer prevention as possessed by reproductive age Nigerian women.

2) The status of usage of cervical cancer screening for cancer prevention by reproductive age Nigerian women.

3) The differences in the status of knowledge and usage of cervical cancer screening for cancer prevention by reproductive age Nigerian women according to marital status

4) The age variations in the status of knowledge and usage of cervical cancer screening for cancer prevention by reproductive age Nigerian women.

5) The religious affilation difference in the status of knowledge and usage of cervical cancer screening for cancer prevention by reproductive age Nigerian women.

6) The status of knowledge and usage of cervical cancer screening for cancer prevention by reproductive age Nigerian women according to educational level.

\subsection{Research Questions}

The following research questions guided the study:

1) What is the status of knowledge of cervical cancer screening for cancer prevention as possessed by reproductive age Nigerian women?

2) What is the status of usage of cervical cancer screening for cancer prevention by reproductive age Nigerian women?

3) What are the differences in the status of knowledge and usage of cervical cancer screening for cancer prevention by reproductive age Nigerian women according to marital status?

4) What are the age variations in the status of knowledge and usage of cervical cancer screening for cancer prevention by reproductive age Nigerian women?

5) What are the religious affilation differences in the status of knowledge and usage of cervical cancer screening for cancer prevention by reproductive age Nigerian women?

6) What are the status of knowledge and usage of cervical cancer screening for cancer prevention by reproductive age Nigerian women according to educational level?

\subsection{Hypotheses}

The following null hypotheses were postulated to guide the study at .05 level of significance at appropriate degree of freedom.

$\mathrm{H}_{1}$ : There is no statistically significant difference in the status of knowledge and usage of cervical cancer screening for cancer prevention by reproductive age Nigerian women based on marital status.

$\mathrm{HO}_{2}$ : Age at birth has no statistically significant difference in the status of knowledge and usage of cervical cancer screening for cancer prevention by reproductive age Nigerian women.

$\mathrm{HO}_{3}$ : Religious affiliation has no significant difference in the status of knowledge and usage of cervical cancer screening for cancer prevention by reproductive age Nigerian women

$\mathrm{HO}_{4}$ : There is no statistically significant difference in the status of knowledge and usage of cervical cancer screening for cancer prevention by reproductive age Nigerian women based on educational level.

\section{Method}

The study was based on descriptive research design and was conducted in Nigeria, from October 2017 to April 2018 (National Population Commission, 2018). The sample size of 1300 reproductive age women was anonymously drawn and surveyed. This was calculated using confidence level of $95 \%$ and confidence interval of 5 (Cohen, Manion, \& Morrison, 2012). The inclusion criteria involved all the women within the age of 15-49 years, as this age bracket was considered reproductive age for all women (Nwala, Ebunoha, \& Ugwu, 2013). Also, this criterion was in line with the recommended age for vaccination against CCa (Markowitz et al., 2007). All the female individuals below the age of 15 and those above 49 years of age were excluded from the study.

Data collection was completed using questionnaire. The study was carried out in all the public health facilities as 
approved by the Nigerian government based on the established criteria. Prior to the distribution of questionnaires, formal introduction of the study was given by the researchers and informed consent obtained from all the prospective participants in the sampled health facilities. A structurally designed questionnaire which was written in English language, was the only instrument used for data collection. The administration and distribution of the questionnaire to all the participants was done by the researchers. The items of the questionnaire were organized to elicit responses from the participants without any bias.

For proper analysis, the data generated was entered into Microsoft Excel and then exported to SPSS 21 for detailed analysis using descriptive statistics. The Committee on Research Grants of the Faculty of Education, University of Nigeria Nsukka gave the approval for the study. [Ethical Approval code: ERA.029]. This is one of the Institutional Review Board Committees of the University that gives approval for studies of this kind and also in accordance with the principles of the Declaration of Helsinki (World Medical Association, 2013). The confidentiality of the participants was protected and no financial commitment was made to them for participating. There was no record of any harm or risks in the study. This is because the data collection process primarily relied on a descriptive non-invasive questionnaire.

\section{Results}

Table 1. Personal information of the participants $(\mathrm{N}=1249)$

\begin{tabular}{llll}
\hline Demographics & & $\mathrm{F}$ & $(\%)$ \\
\hline Marital status & Married & 410 & $(32.8)$ \\
& Single & 695 & $(55.6)$ \\
& Widow & 144 & $(11.5)$ \\
\hline Age at Birth & $15-25$ & 361 & $(28.9)$ \\
& $26-35$ & 673 & $(53.8)$ \\
& $36>$ & 215 & $(17.2)$ \\
\hline Religious Affiliation & Christian & 825 & $(66.0)$ \\
& Muslim & 424 & $(33.9)$ \\
\hline Educational level & No formal education & 53 & $(4.2)$ \\
& Primary & 111 & $(8.8)$ \\
& Secondary & 753 & $(60.2)$ \\
& Tertiary & 322 & $(25.8)$ \\
\hline
\end{tabular}

$F=$ frequency; \%=percentage; $N=$ sample size.

All the participants were Nigerians. There were 1300 reproductive age women that responded to the questionnaire. Of all, 1249(96.1\%) copies of the questionnaire were properly completed and thus used for the final analysis leaving only 51(3.9\%) copies discarded. Among the participants, 695(55.6\%) and 410(32.8\%) were single and married, while only $144(11.5 \%)$ were widows respectively. A total of $673(53.8 \%)$ and $361(28.9 \%)$ participants were within the ages of 26-35 and 15-25 years while only $215(17.2 \%)$ were 35 years plus. Majority of the participants $825(66.0 \%)$ were Christians while only 424(33.9\%) were Muslims. Majority of them $753(60.2 \%)$ and $322(25.8)$ had secondary and tertiary education while only $111(8.8 \%)$ had primary education respectively. Only $53(4.2 \%)$ had No formal education (see Table 1).

Table 2. Showing status of participants' knowledge and usage of cervical cancer screening $(\mathrm{N}=1249)$

\begin{tabular}{lllll}
\hline \multirow{2}{*}{ Parameter } & \multicolumn{3}{l}{ Yes } & \multicolumn{3}{l}{ No } \\
\cline { 2 - 5 } & $\mathrm{F}$ & $(\%)$ & $\mathrm{F}$ & $(\%)$ \\
\hline Knowledge of cervical cancer screening & 1073 & $(85.9)$ & 176 & $(14.1)$ \\
Usage of cervical cancer screening & 513 & $(41.1)$ & 736 & $(58.9)$ \\
\hline
\end{tabular}

$f=$ frequency; $\%=$ percentage $;=$ sample size. 
Majority of the participants $1073(85.9 \%)$ knew about CCa screening while only 176(14.1) did not. Only $513(41.1 \%$ ) had used the CCa screening services while 736(58.9) never used it (see Table 2).

Table 3. Presenting demographic differences on the status of participants' knowledge and usage of cervical cancer screening and significant differences within variables $(\mathrm{N}=1249)$

\begin{tabular}{|c|c|c|c|c|c|c|c|}
\hline \multirow{2}{*}{ Parameters } & & \multirow{3}{*}{$\mathrm{N}$} & \multicolumn{2}{|c|}{ Knowledge } & \multicolumn{2}{|l|}{ Usage } & \multirow{3}{*}{ P-value } \\
\hline & & & Yes & No & Screened & Not Screened & \\
\hline Variables & & & $\mathrm{F}(\%)$ & $\mathrm{F}(\%)$ & $\mathrm{F}(\%)$ & $\mathrm{F}(\%)$ & \\
\hline \multirow{3}{*}{ Marital status } & Married & 410 & $377(92.0)$ & $33(8.0)$ & $124(30.2)$ & $286(69.8)$ & \multirow{3}{*}{$0.34>0.05$} \\
\hline & Single & 695 & $521(75.0)$ & $174(25.0)$ & $226(32.5)$ & $469(67.5)$ & \\
\hline & Widow & 144 & $125(86.8)$ & $19(13.2)$ & $45(31.3)$ & $99(68.7)$ & \\
\hline \multirow{3}{*}{ Age by birth } & $15-25$ & 361 & $288(79.8)$ & $73(20.2)$ & $134(37.1)$ & $227(62.9)$ & \multirow{3}{*}{$0.03<0.05$} \\
\hline & $26-35$ & 673 & $607(90.2)$ & $66(9.8)$ & $255(37.9)$ & $418(62.1)$ & \\
\hline & $36>$ & 215 & $171(79.5)$ & $44(20.5)$ & $33(15.3)$ & $178(82.7)$ & \\
\hline \multirow{2}{*}{ Religion } & Christian & 825 & $703(85.2)$ & $122(14.8)$ & $267(33.4)$ & $558(67.6)$ & \multirow{2}{*}{$0.21>0.05$} \\
\hline & Muslim & 424 & $326(76.9)$ & $98(23.1)$ & $27(6.4)$ & 397(93.6) & \\
\hline \multirow{4}{*}{ Educational level } & No formal & 53 & $37(69.8)$ & $16(30.2)$ & $21(39.6)$ & $32(60.4)$ & \multirow{4}{*}{$0.31>0.05$} \\
\hline & Primary & 111 & $83(74.8)$ & $28(25.2)$ & $42(37.8)$ & $69(62.2)$ & \\
\hline & Secondary & 753 & 681(90.4) & $72(9.6)$ & $255(33.9)$ & $498(66.1)$ & \\
\hline & Tertiary & 322 & 288(89.4) & $34(10.6)$ & $133(41.3)$ & $189(58.7)$ & \\
\hline
\end{tabular}

$S=$ significant $; N S=$ not significant .

The demographic differences on the status of participants' knowledge and usage of the services and significant differences within variables were presented. As shown in the Table, out of the 695 participants who were single, majority 521(75.0\%) knew about the screening services but only few 226(32.5\%) were screened. Among $377(92.0 \%)$ married participants who knew about the CCa screening services, only $124(30.2 \%)$ had been screened. A greater proportion of the widows $125(86.8 \%)$ knew about the service but only $45(31.3 \%)$ had used it. Also, majority: $607(90.2 \%) ; 288(79.8 .0 \%)$; and $171(79.5 \%)$; who were within the ages of $26-35 ; 15-25$; and 36 years plus respectively, knew about the service but only few 255(37.9\%), 134(37.1\%) and 33(15.3\%) within the ages of 26-35 years, 15-25 years and 36 years plus respectively has used the service. Out of 703(85.2\%) Christians and 326(76.9\%) Muslims who knew about the service, only few 267(33.4\%) and 27(6.4\%) indicated been screened. Majority of the participants with secondary $681(90.4 \%)$, tertiary $288(89.4 \%)$, primary $83(74.8)$, and no formal education 37(69.8) knew about the service, but only few 255(33.9\%), 133(41.3\%), 42(37.8\%), and 21(39.6\%), with secondary, tertiary, primary, and no formal education respectively, were screened. A statistically significant difference was observed with regards to age by birth $(\mathrm{P}=0.03<0.05)$ while none existed on marital status $(\mathrm{P}=$ $0.34>0.05)$, religion $(\mathrm{P}=0.21>0.05)$ and educational level $(\mathrm{P}=0.31>0.05)$.

\section{Discussion}

Currently, our study is the first descriptive survey to establish the status of knowledge and usage of CCa screening services by reproductive age women in Nigeria. As a result, the outcome of this study yielded useful facts which may serve as positive steps in designing programs on cervical cancer for women and public health policy making in Nigeria. Of all the participants surveyed, majority was single, aged 26-35 years, Christians and had secondary education. Interestingly, only $4.2 \%$ had no formal education which is a strong indication that the era of people with little or no formal education is gradually fading away. Our study indicated that a good number of the participants knew about cca screening services but only few were screened. The finding is quite surprising as it demonstrates a wider gap existing between what people know about available health service and the subsequent use of such service. This finding is in consistence with other report findings. For instance, in a cross-sectional study involving 260 market women in Nigeria, the respondents exhibited fair knowledge of CCa screening (Ahmed et al., 2013). Similarly, a study from Turkey comprising nursing students in tertiary hospital reported that the participants have theoretical knowledge but not in practice (Uzunla et al., 2013). Also, in a cross-sectional, hospital-based survey 
involving 403 women attending Obstetrics and Gynecology Department of secondary care referral hospitals, it was reported that $62.5 \%$ knew about CCa but $86.6 \%$ never utilized the screening services (Narayana et al., 2017). In contrast, a study on awareness of cervical cancer and screening in a Nigerian female market population indicated that only $19.7 \%$ were aware of CCa screening (Ogunbode \& Ayinde, 2005). Similarly, a study in Polish population among female students reported that the knowledge about cytological screening was poor (Kamzol et al., 2013). In another study, only $16 \%$ of women in Aba, South-Eastern Nigeria knew about CCa screening (Feyi-Waboso, Kamanu \& Aluka, 2005). The similarities and differences as shown in the above findings are clear demonstrations that peoples' knowledge of CCa screening services is quite encouraging but failed to translate the actual usage. Our study therefore suggests that a well-organized public health empowerment program and sensitization campaign on the health benefits of using $\mathrm{CCa}$ screening services by all women, be routinely carried out by the Nigerian government and all the concerned non-governmental organizations as well as agencies in health.

In our study, majority of the participants who were single, aged 26-35 years, Christians and secondary education knew about the screening services but only few were screened. These results demonstrate that the quality of knowledge about a given phenomenon and the usage are greatly enhanced by certain socio-demographics. Our finding is in accordance with the results of other researchers who indicate that socio-demographic variables influenced greatly the outcomes of their researches in varying perspectives (Ogunbode \& Ayinde, 2005; Mutyaba, Mmiro, \& Weiderpass, 2006; Durowade et al., 2012). A statistically significant difference was observed with regards to age by birth while none existed on marital status, religion and educational level. This finding is parallel to study conducted by other researchers which show that adequate knowledge of $\mathrm{CCa}$ screening is linked with socio-demographics (Ogunbode \& Ayinde, 2005; Narayana et al., 2017). In practice, our findings will be useful in designing educational program on knowledge and usage of CCa screening services for women with optimum consideration of socio-demographic differences. The outcome of this study may be attributed to the way or pattern in which awareness campaigns on CCa screening are being organized and carried out in Nigeria.

The strength of the current study lies in its descriptive approach involving reproductive age Nigerian women. Still, there is limitation of our study. Findings of the present study could not be generalized to the larger population of reproductive age women worldwide since the scope was restricted to Nigerian women only. Hence, there is need to carry out similar study in countries other than Nigeria. Finally, a well-programmed public health education and knowledge empowerment focusing on the positive health outcomes of patronizing health services is needed, since greater proportion of the women knew about the service but were unable to use it.

\section{Conclusion}

There is obvious gap between what is known about CCa screening service for cancer prevention and the actual usage by the women. The majority of the women knew about the available service but only few of them had used it. This implies that there is imbalance between the quality of knowledge of a given health service and the actual usage.The outcome of this study should awaken the Nigerian government to mobilize and increase sensitization and awareness campaign on the outstanding preventive roles and positive health benefits of using available health services by all and particularly CCa screening by the women.

\section{Acknowledgments}

None to declare.

\section{Competing Interests Statement}

The authors declare that there are no competing or potential conflicts of interest.

\section{References}

Adewole, I. F., Benedet, J. L., Crain, B. T., \& Follen, M. (2005). Evolving a strategic approach to cervical cancer control in Africa. Gynecologic oncology, 99(3), S209-S212. https://doi.org/10.1016/j.ygyno.2005.07.086

Ahmed, S. A., Sabitu, K., Idris, S. H., \& Ahmed, R. (2013). Knowledge, attitude and practice of cervical cancer screening among market women in Zaria, Nigeria. Niger Med J., 54, 316-319. https://doi.org/10.4103/0300-1652.122337

Anantharaman, V. V., Sudharshini, S., \& Chitra, A. (2013). A cross-sectional study on knowledge, attitude and practice on cervical cancer and screening among female health care providers of Chennai corporation. $J$ Acad Med Sci., 2, 124-8. https://doi.org/10.4103/2249-4855.141132

Bray, F., Ren, J. S., Masuyer, E., \& Ferlay, J. (2013). Global estimates of cancer prevalence for 27 sites in the adult population in 2008. Int $J$ Cancer, 132, 1133-1145. https://doi.org/10.1002/ijc.27711

Cohen, L., Manion, L., \& Morrison, K. (2011). Research methods in education (7th ed.). New York: Routledge 
Taylor \& Francis Group.

Durowade, K. A., Osagbemi, G. K., Salaudeen, A. G., Musa, O. I., Akande, T. M., Babatunde, O. A., ... \& Kolawole, O. M. (2012). Prevalence and risk factors of cervical cancer among women in an urban community of Kwara State, north central Nigeria. Journal of preventive medicine and hygiene, 53(4). PMID: 23469591

Dusek, L., Dvorak, V., Chroust, K., et al. (2018). Epidemiology of cervical cancer in the Czech Republic. Retrieved 9th May, 2019, from www.cervix.cz/index-en.php

Elovainio ,L., Nieminen, P., Miller, A. B. (1997). Impact of cancer screening on women's health. Int J Gynaecol Obstet., 58,137-147. https://doi.org/10.1016/S0020-7292(97)02859-2

Ferlay, J., Soerjomataram, I., Ervik, M., Dikshit, R., Eser, S., Mathers, C., et al. (2013). GLOBOCAN 2012 vl.0, Cancer Incidence and Mortality Worldwide: IARC CancerBase No. 11 Lyon. France: International Agency for Research on Cancer. Retrieved from http://globocan.iarc.fr

Feyi-Waboso, P. A., Kamanu, C., \& Aluka, C. (2005). Awareness and risk factors for cervical cancer among women in Aba, south-eastern Nigeria. Trop J Obstet Gynae., 22, 25-6. http://dx.doi.org/10.4314/tjog.v22i1.14536

Kamzol, W., Jaglarz, K., Tomaszewski, K. A., Puskulluoglu, M., \& Krzemieniecki, K. (2013). Assessment of knowledge about cervical cancer and its prevention among female students aged 17-26 years. Eur J Obstet Gynecol Reprod Bio., 166, 196-203. https://doi.org/10.1016/j.ejogrb.2012.10.019

Mahlck, C. G., Jonsson, H., \& Lenner, P. (1994). Pap smear screening and changes in cervical cancer mortality in Sweden. Int J Gynaecol Obstet., 44, 267-272. $\quad$ PMID: 7909766. https://doi.org/10.1016/0020-7292(94)90177-5

Markowitz, L. E., Dunne, E. F., Saraiya, M., Lawson, H. W., Chesson, H., \& Unger, E. R. (2007). Quadrivalent human papillomavirus vaccine: recommendations of the Advisory Committee on Immunization Practices (ACIP). MMWR Recomm Rep., 2156, 1-24. https://doi.org/10.1037/e601292007-001

Mutyaba, T., Mmiro, F. A., \& Weiderpass, E. (2006). Knowledge, attitudes and practices on cervical cancer screening among the medical workers of Mulago hospital, Uganda. BMC Med Educ., 6, 13. https://doi.org/10.1186/1472-6920-6-13.

Narayana, G., Suchitra, M. J., Sunanda, G., Ramaiah, J. D., Kumar, B. P., \& Veerabhadrappa, K. V. (2017). Knowledge, attitude and practice toward cervical cancer among women attending Obstetrics and Gynecology Department: a cross-sectional, hospital-based survey in South India. Indian J Cancer, 54, 481-487. PMID: 29469083. https://doi.org/10.4103/ijc.IJC_251_17

National Population Commission. Office of the presidency. Nigeria (2018). Research and Statistics Unit, NUP, Federal Capital Territory Abuja.

Nwala, E. K., Ebunoha, N. G., \& Ugwu, U. C. (2013). Consumer knowledge and availability of maternal and child health services: a challenge for achieving MDG 4 and 5 in Southeast Nigeria. BMC Health Services Research, 13, 53. https://doi.org/10.1186/1472-6963-13-53

Ogunbode, O. O., \& Ayinde, O. A. (2005). Awareness of cervical cancer and screening in a Nigerian female market population. Ann Afr Med., 4, 160-163. Retrieved from https://www.ajol.info/index.php/aam/article/view/8354

Sa'aku, B. E., Omaka-Amari, L. N., Agu, M. A., Ugwu, U. P. \& Ugwu, C. U. (2019). Awareness about human papillomavirus as a risk factor for cervical cancer occurrences by female Nigerian undergraduates. Journal of Engineering and Applied Sciences, 12(14), 4231-4234. https://doi.org/10.3923/jeasci.2019.4231-4234.

Uzunlar, Ö., Özyer, Ş., Başer, E., Toğrul, C., Karaca, M., \& Güngör, T. (2013). A survey on human papillomavirus awareness and acceptance of vaccination among nursing students in a tertiary hospital in Ankara, Turkey. Vaccine, 31(17), 2191-2195. https://doi.org/10.1016/j.vaccine.2013.01.033

World Medical Association. (203). Declaration of Helsinki Ethical Principles for Medical Research Involving Human Subjects. JAMA, 310, 2191-2194. https://doi.org/10.1001/jama.2013.281053

\section{Copyrights}

Copyright for this article is retained by the author(s), with first publication rights granted to the journal.

This is an open-access article distributed under the terms and conditions of the Creative Commons Attribution license (http://creativecommons.org/licenses/by/4.0/). 